\title{
IMPLEMENTASI APLIKASI TELEMEDICINE BERBASIS JEJARING SOSIAL DENGAN PEMANFAATAN TEKNOLOGI CLOUD COMPUTING
}

\author{
Mohamad Jamil ${ }^{1}$ Amal Khairan ${ }^{2}$, Achmad Fuad ${ }^{3}$ \\ ${ }^{1,2,3}$ Fakultas Teknik Universitas Khairun \\ jamil@unkhair.ac.id, ibntawakkal@gmail.com, 4ss_@yahoo.com
}

\begin{abstract}
Abstrak - Ide tentang pemeriksaan dan evaluasi kesehatan dengan menggunakan perangkat jaringan telekomunikasi perkembangannya semakin hari semakin meningkat, karena kemajuan di bidang multimedia, imaging, komputer, sistem informasi dan telekomunikasi, salah satunya adalah telemedicine. Secara umum telemedicine adalah penggunaan teknologi informasi dan komunikasi yang digabungkan dengan kepakaran medis untuk memberikan layanan kesehatan, mulai dari konsultasi, diagnosa dan tindakan medis, tanpa terbatas ruang atau dilaksanakan dari jarak jauh. Untuk dapat berjalan dengan baik, sistem ini membutuhkan teknologi komunikasi yang memungkinkan transfer data berupa video, suara, dan gambar secara interaktif yang dilakukan secara real time dengan mengintegrasikannya ke dalam teknologi pendukung video-conference. Termasuk sebagai teknologi pendukung telemedicine adalah teknologi pengolahan citra untuk menganalisis citra medis
\end{abstract}

- Di Indonesia perkembangan teknologi telemedicine menjadi terhambat dikarenakan keterbatasan infrastruktur dan layanan teknologi informasi yang dimiliki belum memadai.

Tujuan dari penelitian ini adalah mendesain dan merealasasikan arsitektur aplikasi telemedicine berbasis jejaring sosial dengan pemanfaatan teknologi cloud computing

Kata Kunci-Telemedicine, Cloud Computing, E-Health, Internet

\section{PENDAHULUAN}

Secara umum telemedicine adalah penggunaan teknologi informasi dan komunikasi yang digabungkan dengan kepakaran medis untuk memberikan layanan kesehatan, mulai dari konsultasi, diagnosa dan tindakan medis, tanpa terbatas ruang atau dilaksanakan dari jarak jauh. Untuk dapat berjalan dengan baik, sistem ini membutuhkan teknologi komunikasi yang memungkinkan transfer data berupa video, suara, dan gambar secara interaktif yang dilakukan secara real time dengan mengintegrasikannya ke dalam teknologi pendukung video-conference [9] perkembangan teknologi telemedicine dalam menganalisis citra medis semakin hari semakin meningkat karena kemajuan di bidang multimedia, imaging, komputer, sistem informasi dan telekomunikasi. beragam. Peralatan kedokteran dapat menghasilkan gambar digital secara langsung, selain itu juga dapat mengubah citra video menjadi citra digital. Kini, Pemanfaatan telemedicine sangat tergantung pada tipe praktek telemedicine. Tipe atau bentuk praktek Telemedicine dapat berupa telekonsultasi, teleassistansi, teleedukasi dan telemonitoring serta telesurgery [10] Di Indonesia perkembangan teknologi telemedicine menjadi terhambat dikarenakan keterbatasan infrastruktur dan layanan teknologi informasi yang dimiliki belum memadai. Kaitannya dengan hal tersebut maka diperlukan integrasi dalam penerapan teknologi telemedicine berbasis Cloud Teknologi Cloud Computing merupakan sebuah upaya untuk meminimalkan biaya pengadaan infrastruktur TI yang cukup besar. Cloud computing merupakan sebuah metode komputasi dimana kemampuan TI disediakan sebagai layanan berbasis internet.[1] Berdasarkan permasalahan yang ada maka dalam penelitian ini akan dilakukan implementasi aplikasi telemedicine berbasis jejaring sosial dengan pemanfaatan teknologi cloud computing. Melalui implementasi ini diharapkan dapat membantu menunjang pelayanan kesehatan kepada masyarakat.

\section{URAIAN PENELITIAN}

\section{A. Defenisi Telemedicine}

Telemedicine adalah praktek kesehatan dengan memakai komunikasi audio, visual dan data, termasuk perawatan, diagnosis, konsultasi dan pengobatan serta pertukaran data medis dan diskusi ilmiah jarak jauh. Berdasarkan pengertian di atas, dapat kita pahami bahwa cakupan telemedicine cukup luas, meliputi penyediaan pelayanan kesehatan jarak jauh (termasuk klinis, pendidikan dan pelayanan administrasi), melalui transfer informasi (audio, video, grafik), dengan menggunakan perangkat-perangkat telekomunikasi (audio-video interaktif dua arah, komputer, dan telemetri) dengan melibatkan dokter, pasien dan pihak-pihak lain. Secara sederhana, telemedicine sesungguhnya telah diaplikasikan ketika terjadi diskusi antara dua dokter membicarakan masalah pasien lewat telepon [2]

\section{B. Cloud Computing}

Komputasi awan (bahasa Inggris: cloud computing) adalah gabungan pemanfaatan teknologi komputer ('komputasi') dan pengembangan berbasis Internet ('awan'). Awan (cloud) adalah metafora dari internet, sebagaimana awan yang sering digambarkan di diagram jaringan komputer. Sebagaimana awan dalam diagram jaringan komputer tersebut, awan (cloud) dalam Cloud Computing juga merupakan abstraksi dari infrastruktur kompleks yang disembunyikannya [3] 


\section{Prinsip Kerja Cloud Computing}

Prinsip kerja Cloud Computing memang sangat efisien, apalagi bagi kalangan bisnis atau perusahaan, hanya dengan menghubungkan perangkat keras (komputer desktop, laptop dll), ke jaringan internet berbasis web. Misalkan sebuah perusahaan membutuhkan media penyimpanan data dengan kapasitas besar yang dibutuhkan untuk kinerja para pengguna (user), maka dengan memanfaatkan cloud computing, data akan tersimpan secara online. Mesin remote yang dimiliki oleh perusahaan akan menjalankan semuanya dari e-mail ke pengolah kata untuk program analisis data yang kompleks ini, dan secara otomatis data akan terkoneksi ke setiap komputer yang terhubung di peusahaan tersebut, dengan demikian setiap user dapat mengakses data melalui internet dengan mudah.

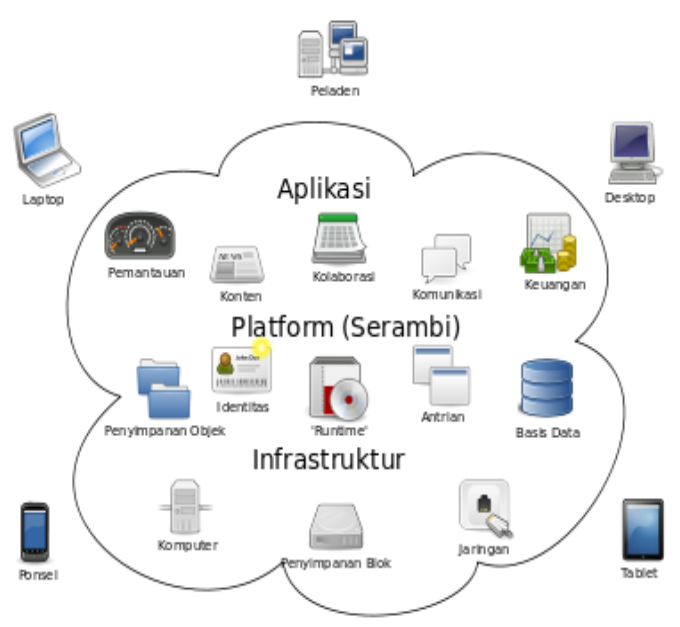

Gambar 1. Diagram Blok Sistem Cloud Computing (id.wikipedia.org)

\section{Model Layanan Cloud Computing}

Menurut NIST dalam Sarna, David E. Y.(2011) model layanan Cloud Computing di bagi menjadi tiga yaitu diantaranya:

a. Cloud Software as a Service (SaaS)

Kemampuan yang diberikan kepada konsumen dengan menggunakan aplikasi penyedia berjalan pada infrastruktur cloud. Aplikasi dapat diakses dari berbagai perangkat klien melalui antarmuka seperti web browser (misalnya, email berbasis web). Konsumen tidak mengelola atau mengendalikan infrastruktur cloud yang digunakan termasuk jaringan, server, sistem operasi, penyimpanan, atau bahkan kemampuan aplikasi individu, dengan kemungkinan pengecualian terbatas terhadap pengaturan konfigurasi aplikasi pengguna tertentu.

\section{b. Cloud Platform as a Service (PaaS)}

Kemampuan yang diberikan kepada konsumen untuk menyebarkan ke infrastruktur cloud aplikasi konsumen yang dibuat atau dikembangkan dengan menggunakan bahasa pemrograman dan alat-alat yang didukung oleh provider. Konsumen tidak mengelola atau mengendalikan infrastruktur cloud yang digunakan termasuk jaringan, server, sistem operasi, atau penyimpanan, namun memiliki kontrol atas aplikasi yang di gunakan dan memungkinkan melakukan konfigurasi aplikasi.

c. Cloud Infrastructure as a Service (IaaS)

Kemampuan yang diberikan kepada konsumen untuk proses penyediaan, penyimpanan, jaringan, dan sumber daya komputasi yang mendasar di mana konsumen dapat menyebarkan dan menjalankan perangkat lunak sesuai dengan keinginan, yang dapat mencakup sistem operasi dan aplikasi. Konsumen tidak mengelola ataupun mengontrol infrastruktur cloud yang digunakan namun memiliki kontrol

atas sistem operasi, penyimpanan, aplikasi yang digunakan, dan kontrol mungkin terbatas komponen jaringan (misalnya, firewall).

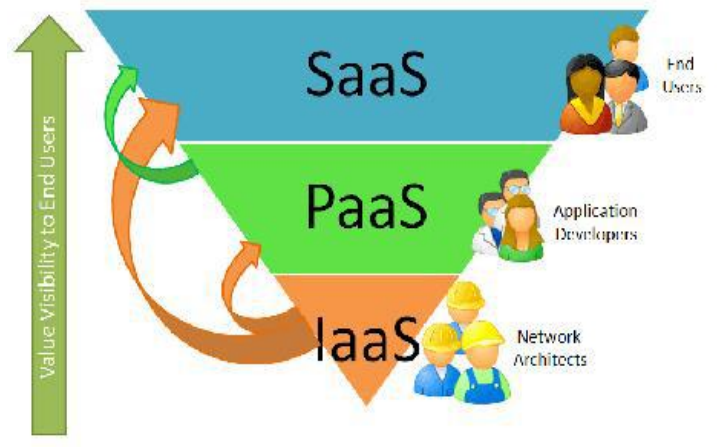

Gambar 2 . Model Layanan Cloud

\section{METODOLOGI PENELITIAN}

\section{A. Tempat dan Waktu Penelitian}

Penelitian dilakukan di dua tempat yakni pada Laboratorium Komputer Fakultas Teknik yang berlokasi di Kampus II Universitas Khairun Ternate dan Rumah Sakit Umum Daerah (RSUD) Chasan Bosoirie Ternate.

\section{B. Alat dan Bahan}

Peralatan utama yang digunakan dalam penelitian ini dapat diuraikan sebagai berikut:

\section{a. Alat:}

1. 2 (dua) buah Personal Computer (client-server)

2. 1 (satu) Buah Acess Point Indoor

3. Hub/Switch 16 Port

4. Antena Outdoor WLAN $2.4 \mathrm{Ghz}$

5. 2 (dua) buah USB WLAN $2.4 \mathrm{Ghz}$

6. UPS

\section{b. Bahan:}

1. Microsoft Windows 7 Starter

2. Proxmox Virtual Environment (VE)

3. Macromedia Dreamweaver 8

4. Microsoft Visio 2003

5. J-COW 


\section{Hosting/Domain}

\section{Tahapan Penelitian}

Penetapan tahapan penelitian harus dibuat terlebih dahulu sebelum melakukan pemecahan masalah terhadap masalah yang sedang dibahas. Dengan demikian penelitian yang dilaksanakan menjadi terarah dan sistematis serta memudahkan dalam menganalisis permasalahan yang sedang dihadapi. Adapun tahapan penelitian dapat dilihat pada bagan alir berikut:

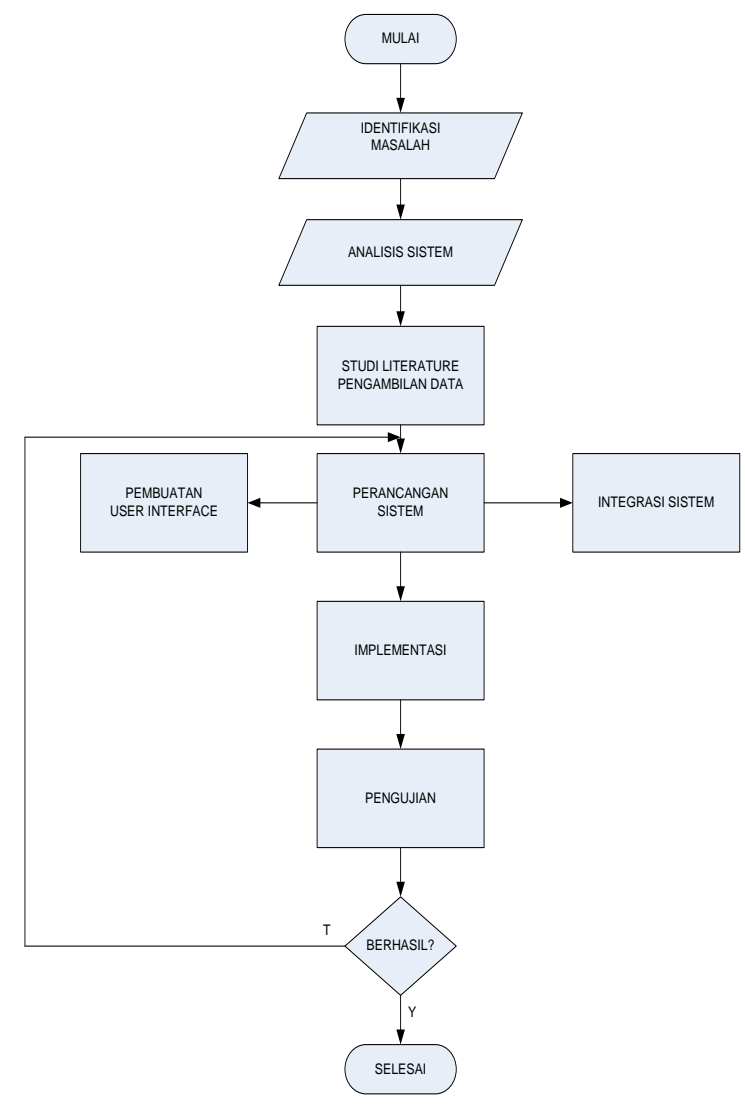

Gambar 3. Flowchart Tahapan Penelitian

\section{Metode}

Metodologi penelitian yang dipakai menggunakan metode PPDIOO yang dikembangkan oleh CISCO dalam sesain sistem jaringan karena dalam penelitian ini dilakukan pengimplementasian pembangunan server cloud dengan menggunakan Proxmox serta pada akhirnya dilakukan optimasi agar sistem berjalan secara

optimal. Fase-fase yang ada dalam metode PPDIOO adalah Prepare, Plan, Design, Implemet, Operate dan Optimize. Gambar 3 menunjukan skema metode PPDIOO [11]. Prepare adalah tahap dilakukannya perencanaan kerja yang dengan baik, dalam segi teknologi yang dibutuhkan maupun strategi yang dipakai untuk membangun server cloud untuk penyediaan webserver. Yang dilakukan adalah mempersiapkan teknologi yang sesuai dengan kebutuhan, melakukan perancangan dan proses Implemntasi Plan adalah tahap dilakukan analisis kebutuhan yang dijadikan sebagai parameter sebelum merancang sebuah sistem jaringan private cloud dengan menggunakan Proxmox sebagai aplikasi untuk membangun dan memanage cloud. Agar kinerja private cloud lebih optimal atau sesuai dengan kebutuhan untuk penyediaan web server maka ditambahkan aplikasi-aplikasi pendukung web server seperti Apache2, PHP5, MySQL 5 dan PhpMyAdmin. Pada fase ini juga dilakukan analisis kebutuhan perangkat keras dan perangkat lunak yang akan digunakan dalam perancangan system yang menggunakan aplikasi Proxmox sebagai aplikasi untuk membangun server cloud.

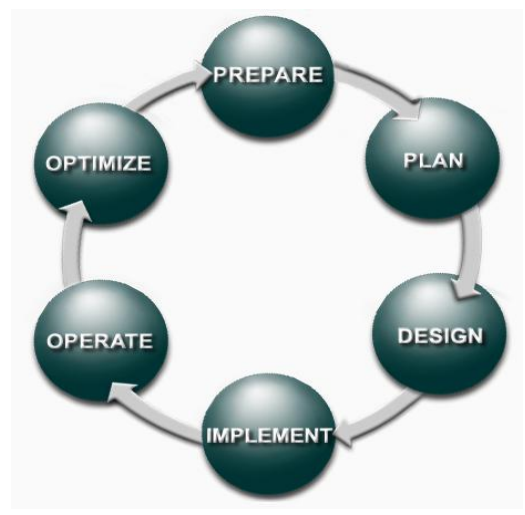

Gambar 4. Skema PPDIOO (Sulistiyowati, 2012)

\section{HASIL DAN PEMBAHASAN}

Model pelayanan kesehatan dan konsultasi medis yang selama ini dilakukan dan terjadi pada Rumah Sakit Umum Daerah (RSUD) Chasan Boesoirie Kota Ternate kepada masyarakat (pasien) masih menggunakan cara-cara konvensional, yaitu seorang pasien ingin meng-konsultasikan penyakit yang di derita maka terlebih dahulu harus ke rumah sakit atau ke tempat praktek dokter yang menangani penyakit yang di derita. Setelah melakukan penelitian mengenai sistem dan model pelayanan kesehatan khususnya tentang menyangkut dengan konsultasi medis di Rumah Sakit Umum Daerah (RSUD) Chasan Boesoirie Kota Ternate, maka didapat beberapa kelemahan, yaitu :

1. Sulitnya masyarakat untuk mendapatkan pelayanan konsultasi medis secara optimal. Hal ini disebabkan karena keterbatasan waktu layanan konsultasi/pemeriksaan kesehatan

2. Masyarakat harus mendatangi Rumah Sakit Sakit atau Tempat Praktek Dokter setempat guna konsultasi medis

Dari keterbatasan sistem yang ada saat ini, maka perlu dikembangkan suatu sistem yang dapat memberikan informasi kepada masyarakat dan juga paramedis guna meng-optimalkan pelayanan kesehatan kepada masyarakat.

\section{A. Desain dan Implementasi Sistem}

Tahap desain sistem memiliki tujuan untuk mengubah model informasi yang telah dibuat selama tahapan analisis menjadi model yang sesuai dengan teknologi yang akan dipergunakan untuk implementasi sistem. Desain sistem pada 
rancangan Aplikasi Telemedicine memiliki dua tahapan yaitu, perancangan arsitektur jaringan, dan instalasi perangkat lunak sistem.

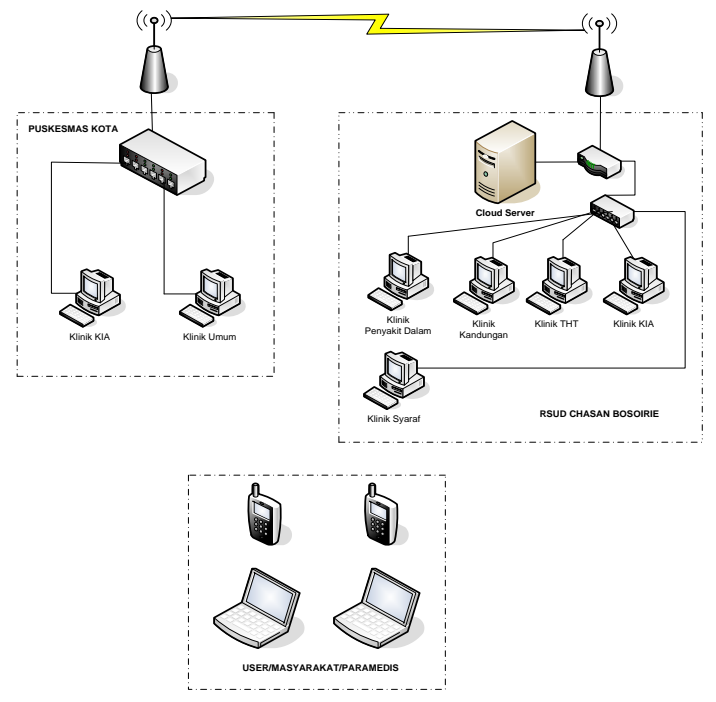

Gambar 5. Arsitektur Jaringan

Tahapan instalasi perangkat lunak dalam penelitian ini dibagi dalam dua tahapan yaitu:

a. Instalasi Proxmox Virtual Environment (VE), merupakan software open source Virtualization Platform untuk menjalankan Virtual Appliance dan Virtual Machine

b. Instalasi dan Setup Jcow sebagai aplikasi telemedicine berbasis jejaring social (social networking)

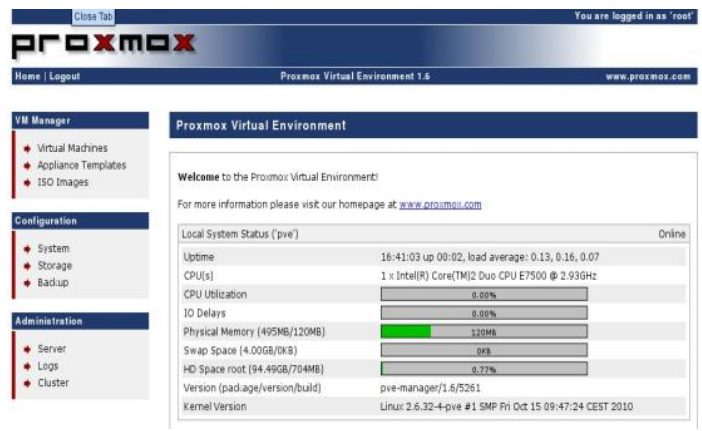

Gambar 6. Tampilan Hasil Instalasi Proxmox

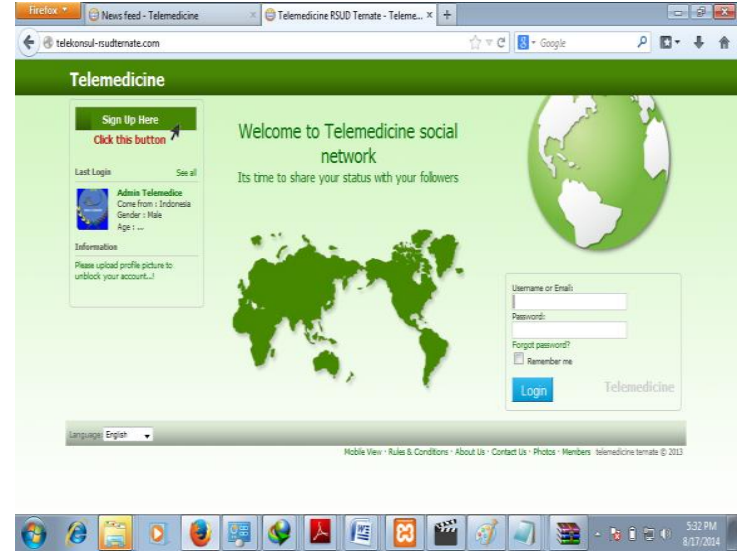

Gambar 7. Tampilan Hasil Instalasi JCOW

\section{KESIMPULAN}

Telemedicine dalam aplikasinya merupakan praktek kesehatan dengan memakai komunikasi audio, visual dan data, termasuk perawatan, diagnosis, konsultasi dan pengobatan serta pertukaran data medis dan diskusi ilmiah jarak jauh. Dalam penelitian ini dapat diambil manfaatnya dengan tawaran kemudahan yang diberikan bagi user karena menggunakan jejaring sosial yang lazim digunakan sebagaimana layanan social network seperti facebook dengan akses data center berbasis teknologi cloud computing. Hanya saja perlu dikembangkan pemanfaatan telemedicine untuk aplikasi yang lebih luas dan berkesinambungan dengan model streaming media online yang kontinyu. Begitu juga pemanfaatan telemedicine untuk daerah-daerah terpencil yang sulit dijangkau oleh berbagai perangkat/teknologi yang ada sekarang. Sebuah tinjauan menarik untuk aplikasi lebih maju yaitu pemanfaatan telemedicine menggunakan teknologi seluler ataupun memanfaatkan komunikasi radio $\mathrm{HF} / \mathrm{VHF}$ untuk jangkauan yang lebih jauh.

\section{DAFTAR PUSTAKA}

[1] Chorbev, I., Sotirovska, M., Mihajlov, D., (2011), Virtual Communities for Diabetes Chronic Disease Healthcare. International Journal of Telemedicine and Applications, Vol. 2011.

[2] Coelho, K. R., (2011), Identifying Telemedicine Services To Improve Access To Specialty Care For The Underserved In The San Francisco Safety Net, International Journal of Telemedicine and Applications, Vol. 2011, 14 pages.

[3] Dobke, M. K., Bhavsar D., Herrera F., (2011), Do Telemedicine Wound Care Specialist Consults Meet the Needs of the Referring Physician? A Survey of Primary Care Providers, International Journal of Telemedicine and Applications, Vol. 2011.

[4] Fabbrocini, G., De Vita, V., Pastore, F., D’Arco, V., Mazzella, C., Annunziata, M. C., Cacciapuoti, S., Mauriello, M. C., Monfrecola, A., (2011), Teledermatology: From Prevention to Diagnosis of Nonmelanoma and Melanoma Skin Cancer, International Journal of Telemedicine and Applications, Vol. 2011, 5 pages.

[5] http://brianrahimsyah.com/instalasi proxmox-virtual-environment-3-0/ diakses tanggal 17 Agustus 2014.

[6] Latifi, Rifat, (2008), Current Principles and Practices of Telemedicine and e-Health, IOS Press.

[7] Purbo, W. Onno, (2011), Petunjuk Praktis Cloud Computing menggunakan Open Source. Vol 1. Jakarta. 
Jurnal Edukasi dan Penelitian Informatika (JEPIN) Vol. 1, No. 1, (2015)

[8] Soegijoko, Soegijardjo, (2005), Development of ICT-Based Mobile Telemedicine System with Multi Communication Links for Urban and Rural Areas in Indonesia, Asia Pacific Development Information Programme, UNDP.

[9] Sri Kusumadewi, dkk, 2009, Informatika Kesehatan, Graha Ilmu dan Rumah Produksi Informatika, Yogyakarta, hlm 41.

[10] Johan Harlan, "Dasar-Dasar Implementasi Telemedicine," Makalah Pusat Studi Informatika Kedokteran Universitas Gunadarma.

[11] Luchi Sulistyowati, Wiwin Sulistyo,Teguh Indra Bayu. 2012. Jurnal Teknologi Informasi-Aiti Vol 9 Nomor 2. Universitas Gunadarma. 